\title{
Memórias e odores: experiências curriculares na formação docente
}

\author{
Maria Inês Petrucci Rosa \\ Tacita Ansanello Ramos
}

Universidade Estadual de Campinas, Faculdade de Educação
Memória é algo quente, memória é algo antigo,

é algo que faz rir, que faz chorar, que a gente se

lembra, que vale ouro...

(Cunha, 2007, p. 99)

\section{Introdução}

Na literatura acadêmica brasileira há uma tradição de investigação sobre processos de formação de professores que se referem prioritariamente aos saberes docentes, saberes da prática, processos reflexivos, formação do professor pesquisador, pesquisa-ação etc. (Geraldi et al., 1998; Nunes, 2001; Lelis, 2001; Borges, 2001; Lüdke, 2001; Gauthier et al., 1998; Tardif, 2002; Rosa, 2004, entre muitos outros). As racionalidades e suas formas de produção de conhecimento são o que prepondera nessa tradição de pesquisa em formação docente. No entanto, também na literatura, há provocações que nos levam a pensar em outros aspectos que parecem ser merecedores de investimento, tendo em vista sua relevância e pertinência no que se refere à formação. Sem nos estender muito nesse ponto, podemos citar pelo menos duas vertentes de trabalho em relação à pesquisa em formação docente que levam em conta esses outros aspectos: a memória e as histórias de vida (Nóvoa, 1992; Goodson, 1992; Oliveira, 2004, entre outros).

Ivor Goodson, em seu artigo "Dar voz ao professor: as histórias de vida dos professores e o seu desenvolvimento profissional", questiona a extrema valorização das investigações sobre a prática pedagógica em processos de formação, que de certa forma apaga a dimensão pessoal da constituição profissional docente (Goodson, 1992). Argumenta a favor da revitalização do olhar para as histórias de vida dos professores, que revelam dilemas, contradições e ambigüidades importantes para a compreensão dos fazeres no cotidiano escolar. Em suas palavras:

Em suma, do que afirmo não deve advir a convicção lógica ou psicológica de que para melhorar a prática se deva inicialmente e imediatamente incidir sobre a prática. Ao invés, defendo o ponto de vista oposto. [...] Devemos, em minha opinião, recordar como a maior parte de nós se sente profundamente inseguro e ansioso acerca do nosso trabalho como professores, quer nas salas de aula, quer nos anfiteatros 
universitários. Estes são, muitas vezes, os locais de maior ansiedade e insegurança - bem como, ocasionalmente, de realização. (idem, p. 68-69)

Tal argumento nos inspira especialmente nas investigações relacionadas com currículo e formação inicial docente. ${ }^{1}$ Nesse contexto, as experiências curriculares relativas aos estágios em instituições escolares são muitas vezes decisivas e cruciais na formação da identidade docente. Em nosso grupo de pesquisa na Faculdade Educação da Universidade Estadual de Campinas (UNICAMP), o trabalho de Corradi (2005) mostra como o estágio nas licenciaturas marca intensamente a formação de múltiplas identidades docentes no entrecruzamento das várias culturas em jogo, em especial a escolar e a científica (Rosa \& Corradi, 2007).

Ainda considerando a cultura como ponto de partida, em nossa experiência docente na universidade na supervisão de estágios nas licenciaturas, observamos com freqüência a insegurança e o receio dos professores em formação inicial ao se depararem com a complexidade do cotidiano da escola (Rosa \& Tosta, 2005). Temos como hipótese que é possível refletir sobre tais sentimentos no contato com essa complexidade através da rememoração das histórias de vida, principalmente, as escolares. No entrecruzamento entre histórias de vida e memória na formação docente, concordamos com os questionamentos:

Que lembranças têm os professores do cotidiano das escolas que fizeram parte de sua formação? Que práticas e que modelos lhe acionaram dispositivos de produção do ser professor? Que professores e que performances são lembradas através do trabalho da memória? (Oliveira, 2004, p. 14)

Como já discutimos em Rosa e Corradi (2007), o estágio é o tempo/espaço de contato do licenciando

${ }^{1}$ Chamamos de formação inicial docente aquela que se dá em programas de graduação, seja licenciatura ou pedagogia, em instituições universitárias. com o mundo vivo da instituição educativa, em que o constituir-se professor vai acontecendo à medida que experiências vão tomando formas e significados. O estágio aproxima-se da idéia de experiência, na medida em que:

A experiência é o que nos passa, o que nos acontece, o que nos toca. Não o que se passa, não o que acontece, ou o que toca. A cada dia se passam muitas coisas, porém, ao mesmo tempo, quase nada nos acontece. Dir-se-ia que tudo o que se passa está organizado para que nada nos aconteça. (Larrosa, 2002, p. 21)

Nesse sentido, a pesquisa aqui relatada traz possibilidades formativas oportunizadas pelo estágio curricular da licenciatura, compreendido como experiência, como acontecimento que pode marcar a constituição dos sujeitos docentes a partir de processos de rememoração.

\section{$O$ contexto da pesquisa e a questão de investigação}

Nesse cenário constituído pela valorização das histórias de vida como aspecto essencial de seus processos de formação, procuramos investigar como as memórias escolares de alunos de licenciatura podem ser compartilhadas na experiência do estágio, tendo em vista uma aproximação mais significativa com os fazeres do cotidiano escolar.

Metodologicamente, aproximamos o foco da pesquisa de uma perspectiva que questiona a clássica abordagem de produção de conhecimentos a partir do olhar, da observação. O olhar, viés próprio da ciência moderna, de certa forma restringe possibilidades outras de conhecer e produzir realidade. Como aponta Veiga-Neto:

As metáforas ligadas à visão têm sido muito importantes na nossa tradição cultural na medida em que a visão tem sido celebrada enquanto sentido privilegiado capaz de fazer uma mediação acurada e fidedigna entre nós e a realidade, ou seja, mostrar como é mesmo o mundo. (2002, p. 24) 
No contexto do estágio, cenário de nossa pesquisa, é usual nos currículos de formação de professores a idéia de que as atividades devam sempre ser registradas em diário de campo a partir de um olhar extremamente apurado sobre os acontecimentos da escola. Nesse caso, a visão é o sentido que prepondera no contato com os ambientes, participando dos processos de produção de conhecimentos profissionais docentes. Como afirma Fujikawa:

Os registros podem gerar mudanças na prática - a análise do que foi registrado (e, portanto, teorizado, sentido, praticado) permite um distanciamento do autor com sua "obra". Na medida em que analisa, avalia, tenta enxergar a teoria que "iluminou" as suas ações... (2005, p. 250, grifo nosso)

Ainda em nossa trilha metodológica, ao recusarmos a visão como acionadora de memórias escolares, aproximamo-nos da provocação expressa por Peter Burke em seu artigo "Uma história cultural dos odores". Nesse trabalho, Burke levanta um conjunto de contextos, situações e elementos da cultura que se expressam a partir de um panorama de odores. O olfato como sentido e os odores como sensibilidades transmutam-se em expressões da memória, que pode entrecruzar tempos e espaços re-significando experiências.

Ainda lembro vivamente de um odor da minha infância, o cheiro azedo que impregnava as ruas dos bairros pobres por onde eu passava a caminho da escola. Marcel Proust, como não poderia deixar de ser, dava muita atenção aos odores assim como ao sabor de sua célebre madeleine, e alguns anos, caminhando por Hong Kong, tive o que se poderia chamar de experiência proustiana. (Burke, 2004, p. 1)

Nessa perspectiva e com a intenção de exercitarmos a possibilidade da escrita de histórias narrativas a partir dos odores, foram propostas as seguintes questões aos alunos estagiários de uma turma de licenciatura: que odores são sentidos no ambiente da escola onde se realiza seu estágio? Que memórias são acionadas a partir desses odores?
Essa proposta aconteceu logo após o início das atividades de estágio em diferentes instituições escolares. Os estagiários estavam ainda em fase de estabelecer uma rotina de trabalho dentro dessas escolas, ou seja, encontravam-se ainda num momento de reaproximação desses contextos, onde antes foram estudantes e agora voltavam na condição de professores em formação. Participaram desta pesquisa dez estagiários de cursos de licenciaturas da UNICAMP.

\section{Memória e currículo as contribuições teóricas de W. Benjamin e de I. Goodson}

Entendendo a memória como cenário para o entrecruzamento de espaços e tempos, é através dela que nos tornamos sujeitos da experiência coletiva - por ser vivenciada sempre na relação com os outros mas também individual - pois cada acontecimento é produtor de diferentes significados para os que os vivenciam.

A rememoração articula a dimensão sensível da memória ao ato de lembrar, o que torna comunicável a experiência. Na rememoração as lembranças estão sujeitas a atualizações, releituras e reelaborações, fruto de reflexões sobre o acontecimento lembrado. (Pérez, 2003, p. 5)

Para o filósofo Walter Benjamin, a memória não significa apenas acontecimentos e lembranças, mas sim experiência, afetividade, sensibilidade, subjetividade, esquecimento, entrecruzamento de sujeitos e, principalmente, experiências vividas. $\mathrm{O}$ ato de rememorar possibilita que dimensões pessoais que foram perdidas com o avanço do mundo moderno e capitalista sejam recuperadas na relação temporal entre passado, presente e futuro. Rememorar é partir de indagações e trazer o passado como possibilidade de construir rumos atentos para presente e futuro.

A pessoa que rememora, para Benjamin, é mais inteira, possui sensibilidades, esquecimentos e incompletudes e se percebe como portadora de experiências e como sujeito que se constrói sempre na relação com o 
outro. Dessa forma, trabalhar a memória não é tomá-la como ferramenta de pesquisa, mas como cenário. Para Benjamin, a "memória constitui uma viagem no tempo, até as impressões 'matinais' da pessoa humana, com direito à ida e à volta" (Galzerani, 1999, p. 102).

Ainda numa perspectiva benjaminiana, na sociedade capitalista, com o intenso transitar entre as pessoas e a mecanização de nossos atos pelo tempo, muitas vezes nos esquecemos de observar o lugar por onde passamos, as pessoas com as quais conversamos e deixamos de experienciar odores exalados nos diferentes ambientes, nos quais costumamos estar cotidianamente.

Em outras palavras, as ações mecânicas passam a tornar o mundo pobre no narrar das experiências. Absorver tudo sem pensar no que está sendo visto e feito, sem tirar disso experiência, mas apenas vivência e reprodução, é o modo que vivemos hoje, num sistema maquinário que nos impele a partir para a frente, a começar de novo, a contentar-se com pouco, a construir com pouco.

Pobreza de experiência: não se deve imaginar que os homens aspirem a novas experiências. Não, eles aspiram a libertar-se de toda experiência, aspiram a um mundo em que possam ostentar tão pura e tão claramente sua pobreza externa e interna, que algo de decente possa resultar disso. (Benjamin, 1989, p. 118)

Cada escola, cada casa, cada cidade possui determinados odores para quem ali vive - alguns sentidos de forma particular e outros num contexto coletivo. Essa condição possibilita que memórias sejam revividas e re-significadas à medida que o sujeito da experiência possa, de olhos fechados, identificar determinado lugar por seus odores característicos.

É possível escrever uma história dos odores? Que certos lugares e períodos são marcados por diferentes "panoramas de odores" é algo que muitos de nós, ao menos os que têm mais de 50 anos, sabem por experiência própria. Cada cidade ou cada agrupamento regional de cidades possui odores característicos: em Araraquara, por exemplo, sobressai o cheiro de laranja, e na São Paulo dos anos de 1980, quando havia mais carros movidos a álcool do que hoje, era possível sentir, já no aeroporto, um cheiro doce inconfundível - a ponto de eu não ter a menor dúvida de que, mesmo se chegasse de olhos vendados, saberia em que cidade me encontrava.

(Burke, 2004, p. 1)

Ainda na perspectiva de Benjamin, o ato de narrar não é relatar algo com saudosismo, mas trazer as experiências no plural e trazer à tona as antigas narrativas do ponto de vista cultural. A arte da narrativa está em evitar explicações sobre o dito. O leitor é livre para interpretar o narrado como quiser, podendo este atingir uma amplitude que não existe na informação.

Para Michel de Certeau, ao falarmos ou ao narrarmos, estamos praticando uma arte, e essa arte produz efeitos. Assim, o narrar não seria um retorno à descrição, mas um ato que procura, distanciando-se cautelosamente da realidade, provocá-la. Nas palavras do autor: "mais que descrever um 'golpe', ela (a narrativa) o faz" (Certeau, 1994, p. 153). E ao fazer o golpe, ao praticar a astúcia, essa arte pode assumir múltiplos desdobramentos. Sendo arte, exige criação; sendo astuta, pode se engendrar com ousadia.

Dessa forma, o narrador benjaminiano traz consigo a característica do saber aconselhar, que é entendida menos como uma forma de saber responder perguntas do que dar sugestões. No entanto, Benjamin também ressalta que no mundo em que vivemos o aconselhamento está se apagando e tornando-se antiquado, visto que as experiências estão sendo cada vez menos comunicáveis.

A narrativa, que durante tanto tempo floresceu num meio de artesãos - no campo, no mar e na cidade -, é ela própria, num certo sentido, uma forma artesanal de comunicação. Ela não está interessada em transmitir o "puro em si” da coisa narrada como uma informação ou um relatório. Ela mergulha a coisa na vida do narrador para em seguida retirá-la dele. Assim se imprime na narrativa a marca do narrador, como a mão do oleiro na argila do vaso. (Benjamin, 1989, p. 205) 
Neste trabalho, defendemos a idéia de que a formação docente passa também pelas memórias, muitas vezes inusitadas, pelas experiências comunicáveis e pelas sensibilidades dos professores em formação. Nesse sentido, currículo não é aquilo que se programa, que se prevê e se controla nas atividades de formação que ocorrem tanto no âmbito da universidade, como nos cenários dos campos de estágio. Isso amplia a noção de currículo que abandona a restrita noção de currículo prescritivo, dirigindo-se para outra: a aprendizagem narrativa.

A mudança de currículo que estamos analisando é a passagem de uma aprendizagem primária e de um currículo prescritivo para uma aprendizagem terciária e um currículo narrativo. Tal mudança se acelerará rapidamente à medida que ocorra a mudança para uma organização econômica flexível. A inércia contextual de um currículo prescritivo, baseado em conteúdo, não resistirá às rápidas transformações da nova ordem do mundo globalizado. (Goodson, 2007, p. 251)

\section{E ainda:}

No novo futuro social, devemos esperar que o currículo se comprometa com as missões, paixões e propósitos que as pessoas articulam em suas vidas. Isto seria verdadeiramente um currículo para empoderamento. (idem, ibidem)

Concordamos aqui novamente com Goodson quando traz a noção de um currículo narrativo e essa assunção é o que nos move. No caso dos estágios nas licenciaturas, o currículo narrativo pode expressar-se também em um leque de experiências vividas e entretecidas no diálogo com os formadores, principalmente, supervisores de estágio e professores tutores. ${ }^{2}$

Nesse contexto, ao assumir tais noções e sensibilidades a respeito de currículo narrativo, formação do-

${ }^{2}$ Chamamos professores tutores àqueles professores experientes que recebem estagiários nas escolas, abrindo as portas de suas salas de aulas, compartilhando experiências e orientando atividades relacionadas com o próprio estágio. cente e memórias, passamos a apresentar as narrativas dos estagiários envolvidos nesta pesquisa, buscando tessituras e brechas que possibilitem saber mais sobre seus processos de profissionalização.

\section{Experiências narradas a partir dos odores sentidos nos campos de estágio: a expressão através de mônadas}

Os estagiários de licenciatura que participaram desta pesquisa foram levados a revisitar seus campos de estágio, percorrendo as dependências da escola, visitando diferentes ambientes, com a sensibilidade focada nos odores. A partir dos odores sentidos, escreveram textos narrativos em que relacionaram o que sentiram no campo de estágio e as memórias acionadas a partir disso.

As narrativas produzidas pelos estagiários são apresentadas, neste trabalho, na forma de mônadas. Numa perspectiva benjaminiana, mônadas são pequenas crônicas que guardam consigo fragmentos de histórias mas que, juntas, exibem a capacidade de dar sentidos a um contexto maior. ${ }^{3}$ Trabalhar com mônadas potencializa, do ponto de vista metodológico, a produção de um espectro de significados. Tal assunção é inspirada também no que Galzerani aponta:

No que diz respeito à produção de memórias ou produção de conhecimento histórico em Walter Benjamin, passamos a mergulhar em algumas "mônadas" ou miniaturas de significados - conceito que o pensador ora focalizado coloca em ação no diálogo com o físico Leibnitz. Tais centelhas de sentido [...] podem ter a força de um relâmpago. (2002, p. 62)

Perfume de mulher

Senti um cheiro bastante agradável de perfume feminino, bem parecido com o que eu sentia quando me aproximava

${ }^{3}$ No texto Infância em Berlim - por volta de 1900, Benjamin apresenta memórias de sua infância em forma de mônadas, com uma escrita cheia de sensibilidade e de entrecruzamento de tempos e sujeitos que consegue retratar o cenário sócio-histórico de seu país no início do século XX. 
da professora de língua portuguesa na sexta série. O odor não só me fez relembrar dela como até mesmo as cores de sua roupa, sua voz, sua aparência sempre cuidada; parecia até que eu sentia sua presença ao meu lado, ao mesmo tempo que sentia uma saudade muito forte daquela época em que brincávamos eu e meus colegas, e eu tinha bem menos preocupações do que hoje.

Um outro odor que senti foi o da borracha apagadora. $O$ cheiro em si foi idêntico ao que sinto nos meus estudos atuais; no entanto o ambiente cercado de jovens, da professora e da matéria, que antigamente era tão difícil, me fez voltar à época em que eu era um aluno do Ensino Médio e senti a dificuldade de compreender a matéria da época, já que antigamente eu sabia bem menos do que atualmente, mas a dificuldade era compensada pelo forte vínculo de amizade que agora não há mais entre os colegas. (Adriano) ${ }^{4}$

Poeira, sujeira e livros

Poeira. Sujeira. Livros. Isso foi o que encontrei-e de certa forma, me lembrei-ao retornar à biblioteca de uma escola pública. O cheiro da poeira me fez pensar em três momentos distintos da minha vida, e todos eles, com suas respectivas ressalvas, relacionavam-se à questão do ensino.

Ao sentir meu nariz coçar dentro da biblioteca, me revi mexendo nos livros de matemática dos meus tios, que estavam encaixotados no porão da casa velha da minha avó, mais ou menos aos sete anos de idade. Resolvi levá-los para casa para usá-los quando eu me tornasse professora de Matemática, assim como eles. Acredito que este tenha sido um dos primeiros momentos em que eu tomei consciência do que eu queria ser quando crescesse: professora. Tais livros me acompanharam por muito tempo em minhas brincadeiras de escolinha com as minhas bonecas.

A sujeira me lembrou de que, mais tarde, quando eu já estava no ginásio, a escola estava doando os livros antigos da biblioteca para que houvesse lugar para acomodar alguns novos títulos, e eu, num ímpeto inocente da vontade ensinar, pensei: "Ah, vou lá buscar alguns livros pra eu usar quando for professora”. Na época, eu ainda queria ser professora de Matemática, e por isso levei uns cinco livros de Mate-

${ }^{4}$ Os nomes utilizados para identificar os estagiários de licenciatura são fictícios. mática já ultrapassada para casa. E os tenho até hoje. E havia o cheiro de poeira daquela biblioteca bagunçada, $e$ sujeira na minha mão por ter mexido naqueles livros - assim como havia acontecido no porão da minha avó, assim como aconteceu essa semana.

Nesse ponto é que me deparei com o terceiro momento: $o$ de agora. Que é que estava eu fazendo na biblioteca da escola? Procurando livros para meu projeto de estágio. E os encontrei: sujos e empoeirados como das outras vezes. A diferença é que agora eu realmente vou utilizá-los para dar uma aula - mas dessa vez será de verdade. (Moira)

O giz

Foi quando, de repente, ali estava, bem diante de mim na lousa, aquele pedaço calcário de história, nostálgico... Sim, muito tempo se passou, mas um detalhe ainda persiste: o giz de lousa. Quem diria que aquele toco branco me traria tão boas lembranças? Pois é, trouxe, e com ele veio um gancho para o cheiro de pó de giz que sempre ficava na sala de aula quando a professora apagava a lousa. As finas partículas em suspensão no ar pairavam até que algum pobre aluno as captava com o nariz. Todos odiavam; alguns, como eu, começavam um ataque, em conjunto, de espirros, quase que como em um campeonato em que participavam apenas pessoas alérgicas. (Pedro)

Aroma adocicado e cheiro de comida

Um dos odores que senti foi o do perfume de uma garota que estava conversando com um rapaz na entrada do prédio. Era um aroma floral bem adocicado que me lembrou o perfume que as meninas da minha turma de ginásio usavam. Esse perfume também me fez lembrar do meu primeiro namoro com uma colega de escola, pois ela usava um perfume que também era doce, no entanto, mais suave.

Outra lembrança que me veio à mente está ligada ao cheirinho gostoso da cantina da escola, pois na época em que estudei na ETECAP (Escola Técnica Estadual Conselheiro Antônio Prado $)^{5}$ fazendo o curso técnico em Química, sem-

${ }^{5}$ A Escola Técnica Estadual Conselheiro Antônio Prado é mantida atualmente pela Fundação Paula Souza, em São Paulo, com verbas públicas e oferece cursos técnicos nas áreas de bioquímica, química e meio ambiente, além do ensino médio. 
pre ia direto do trabalho para a escola e parava na cantina para comer alguma coisa e bater um papo com o pessoal do curso. Aquele cheiro gostoso de lanche esquentado na chapa não tem como esquecer, assim como as conversas que tínhamos naquele lugar. (André)

Os momentos mais gostosos de minha adolescência

Na semana seguinte voltei à escola totalmente desligada do trabalho que deveria fazer, pensava apenas no estágio e no que iríamos conversar com a professora. Sem perceber, assim que entramos na escola me lembrei de como era a entrada na sala de aula durante meu Ensino Fundamental. Só então associei que aquela lembrança tinha vindo à tona devido ao cheiro de produto de limpeza que estava sentindo, o qual era parecido com o cheiro que a minha antiga sala de aula tinha quando chegávamos logo pela manhã.

Nesse dia, a professora estava aplicando prova para os alunos e nos pediu para conversar sobre o projeto do estágio fora da sala de aula. Sentamos próximo à cantina e começamos a conversar. O cheiro dos salgados me fez relembrar intermináveis conversas que mantinha com minhas amigas na lanchonete da escola no Ensino Médio. Acredito que a situação na qual eu me encontrava conversando com a professora e outra estagiária no pátio da escola contribuiu, junto com os odores do ambiente, para que me lembrasse de conversas ocorridas há seis anos.

Então as faxineiras da escola começaram a lavar a quadra da escola, muito próxima de onde estávamos conversando. Comecei a sentir um cheiro que eu adoro até hoje: cheiro de terra molhada. Eu adoro esse cheiro devido a um episódio que aconteceu comigo e com minhas amigas no Ensino Médio, o qual eu considero um dos momentos mais gostosos da minha adolescência. Nós estávamos brincando de "mãe da rua" na quadra de vôlei de areia da escola e começamos a sentir aquele cheiro de terra molhada indicando que começava a chover. Naquele dia, sem pensar em nada, continuamos a brincar, mesmo com a chuva. Depois fomos obrigadas a ficar, durante todas as aulas seguintes fora da sala, pois não podíamos assistir à aula naquela situação: molhadas e sujas. Aquela tarde de cumplicidade foi o ápice de nossa amizade. (Helena)
Solidão

Outro cheiro que me despertou atenção foi o de giz, e isso me remete aos momentos de auto-exclusão que vivi. Quando sentava na primeira carteira para assistir à aula, o giz entrava na minha garganta, que ficava bem ressecada. No entanto, tive até momentos bons com todo esse giz, pois foi graças a ele que hoje eu tenho vontade de dar aulas. O principal odor, e o que me fez lembrar dos piores momentos da minha estada no colégio, foi o dos lanches na cantina. Eles me lembravam o quão solitários eram os meus recreios. Eram os momentos do dia em que eu tinha vontade de me esconder, de ir embora daquela escola. Passava todo o intervalo comendo o meu lanche (com muito sacrifício, pois para comprá-lo tinha que enfrentar uma fila onde todos se empurravam), vendo aquele "mar de gente" andando e, aproveitando o único momento de diversão na escola, sozinho. (Danilo)

$O$ retorno à escola de origem

A ETECAP, meu local de estágio, reaviva em mim algo de adolescência, um momento ótimo da minha vida, já que por três anos estudei lá. O cheiro dos laboratórios me faz lembrar de episódios de molecagem, como quando saíamos para o intervalo sem tirar o avental branco e, sem a inspetora ver, subíamos na amoreira. Quando voltávamos para o laboratório, estávamos todos roxos por causa das amoras. O cheiro da terra, da grama molhada me lembra um mês de julho que fez muito, muito frio, e ia todo mundo "encapotado", com direito a luvas e touca. Ao chegar pela manhã e ir para o pátio, vi aquele campo de futebol branquinho que parecia neve. Foi irresistível não ir até lá, tirar a luva e pegar na grama. O cheiro da cantina e do marmiteiro me lembrou que, por vezes, pedia carona até o centro da cidade. Isso fazia com que eu economizasse o dinheiro da passagem, que na sexta-feira, eu usava para almoçar um "lanche no prato" com o pessoal, na cantina. Os vestiários e o cheiro de sabonete me lembram as aulas de Educação Física. Tínhamos que dar umas vinte voltas na pista de atletismo, sob um sol "de rachar”, com tempo medido para ganhar nota! Era terrível! Ah! A professora Lúcia! E quando a gente estava debaixo do chuveiro com os cabelos cheios de xampu, os meninos fechavam o registro da água que era fornecida para os banheiros femininos e a gente ficava gritando debaixo dos chuveiros e xingando... (Amanda) 
Uma escola feita de madeira

Ao freqüentar a escola, tive algumas lembranças da época em que fiz o Ensino Fundamental. Estudei em um colégio de padres: o Liceu. Era um colégio bastante grande e relativamente antigo. O colégio tinha sido fundado há mais de um século e a maioria das salas de aulas possuía chão de madeira. $O$ cheiro de madeira nas salas de aula era, portanto, bastante acentuado. O chão da sala de aula do colégio que estou freqüentando é de madeira. Esse cheiro de madeira me faz lembrar das aulas que eu tinha no Liceu. Quando me recordo das aulas do Ensino Fundamental, me vem à memória a imagem das salas, as quais eram muito grandes e possuíam um aspecto bastante antigo. Outra memória que tenho relacionada com odores é produzida com o cheiro da cantina. Quando, na minha infância, os alunos iam para o recreio, todos compravam lanche na cantina da escola e depois se reuniam no campo de futebol para lanchar juntos. Esse momento de entrosamento e recreação com os meus amigos era muito marcante. Uma curiosidade é que os alunos sempre pediam um mesmo salgado específico na cantina, cujo cheiro me veio à mente na cantina da escola que eu visitei como estagiária. (Nara)

Memórias olfativas não revivenciadas

Os odores característicos da minha infância e adolescência no ambiente escolar são incontáveis. A escola onde cursei o Ensino Fundamental guarda minhas melhores lembranças olfativas: o cheiro da merenda que inquietava os últimos minutos antes do intervalo, o sufocante odor da poeira que subia nas peladas improvisadas em um "campinho" ( um terrão atrás da escola com traves feitas de mochila ), o insuportável cheiro do banheiro masculino no final de intervalo e o inesquecível cheiro da goiabeira que jogava de centroavante em nossas peladas e que fornecia as "munições" das lendárias guerras de goiaba (tudo isso acontecia no intervalo).

O colégio onde cursei o Ensino Médio não me traz tantas lembranças, mas existe uma explicação convincente: ele ficava do lado de uma fecularia e o cheiro de farinha imperava na escola.

Ao retornar para esta última escola, parece frustrante, mas, apesar de me esforçar, não consegui encontrar um odor que lembrasse aqueles tempos, salvo o cheiro da cantina, que era parecido com a do colégio do Ensino Fundamental (que nem era uma cantina, mas um bar sujo que ficava de frente para a escola) e da biblioteca, que cheirava a pó como qualquer outra que conheço.

Nem mesmo o banheiro, que pelo menos tinha o mesmo aspecto, tinha um odor parecido. Por fim, me dei por vencido; apesar de minhas inúmeras experiências olfativas, das quais ainda me recordo, infelizmente não fui contemplado em revivê-las. Espero que outros tenham tido a felicidade de reviver esses momentos. (Luciano)

Combinação que desperta saudades

Odores da escola... A escola em que estou estagiária é a mesma em que cursei o Ensino Médio. Trata-se de uma escola técnica de Química; por isso, andando pela escola, sentindo o cheiro próximo aos laboratórios, foi inevitável lembrar-me das minhas aulas práticas. Ah! O tempo em que eu, curiosa e ao mesmo tempo confusa (será que gosto mesmo de Química?), queria saber o que iria ocorrer dentro daqueles tubos de ensaio das aulas de Química Orgânica. O tempo em que os colegas de turma também não sabiam e nos reuníamos aos sábados para "decifrar" o que era "aquilo" tão misterioso...

Boa época. Etapa importante na decisão profissional de cursar Química na universidade.

Continuando a caminhada pela escola, chegando perto da cantina... Ah, a cantina... Lugar onde não apenas eram feitas as refeições mas também onde me sentia mais à vontade. O cheiro agradável dos salgados, o ambiente com amigos muito me fizeram lembrar a casa da minha avó, ambiente igualmente aconchegante e cheio de amigos.

Os odores da escola despertam várias memórias. $O$ andar pelos corredores arborizados remeteu-me à infância. Época sem responsabilidades, sem preocupações, que subia e descia de árvores em velocidade incrível, em que podia, sem exagero, passar a tarde inteira em cima das árvores pensando na vida. Ou dormindo, mais provável. O cheiro daquelas árvores fez-me lembrar também dos meus colegas e eu, no Ensino Médio, fazendo piqueniques sob as árvores e estudando, com um pouco de desespero, na hora do almoço, a nomenclatura de ácidos inorgânicos.

Odores da escola. Lembrança de várias etapas da minha vida. Lembranças da escola, com meus amigos e professores, 
memórias da infância. Memórias... Escola... Combinação que desperta saudades. (Melissa)

As memórias de escola produzidas em forma de narrativa pelos estudantes estagiários não nos levam a generalizações, tampouco a explicações. O exercício de adensamento das narrativas não deve ser feito com a finalidade de apontar erros ou acertos, mas como forma de trazer vivências e rememorações cheias de significados, que possuem o entrecruzamento de tempos, espaços e visões. Mesmo nesse contexto de considerações, é possível tecer alguns argumentos a partir das mônadas aqui explicitadas.

\section{Formação docente e memória: que cruzamentos?}

Nas memórias declaradas através de brechas nas mônadas, é possível perceber a escola como lugar de amizade, de encontro, de diferentes possibilidades e oportunidades em termos de socialização. Há quase um tom de nostalgia nas narrativas que contam, por exemplo, de uma professora de "aparência sempre cuidada", seu perfume e sua voz. Ou ainda as sensações produzidas pelo pó de giz pairando no ar "até que algum pobre aluno as captava com o nariz" ou entrasse "na garganta, que ficava bem ressecada".

É interessante também notar, nas memórias relacionadas com odores presentes em ambientes escolares, as narrativas que trazem o cheiro da cantina, a alimentação, os momentos de encontro com colegas ou ainda a cantina como cenário da constatação da solidão, a possibilidade de ter a escola como espaço de socialização e de intensificação de vínculos, sejam ligados a amizades, sejam ligados a namoros. A escola fica na memória como lugar de vida acontecendo em suas múltiplas aproximações e entrecruzamentos.

Ao rememorar encontros e desencontros, os professores em formação, imersos no ambiente escolar na perspectiva do estágio, passam pela experiência de um outro encontro. $\mathrm{O}$ encontro consigo mesmo, com o estudante em instituições escolares de ensino básico que, a partir dessa experiência, optou um dia em ser pro- fessor. Essa opção parece residir na memória, que não é puramente racional ou do campo dos conhecimentos, mas sim pertencente à sensibilidade e à estética.

O olfato oferece uma via alternativa de sensibilidade, de contato sensorial com o mundo material. Esse contato propicia inusitadas e ricas reflexões nos professores em formação inicial, que se encontram desafiados a entrar nas escolas não mais como estudantes, mas como docentes.

Nesse sentido, as memórias produzidas pelos odores nos possibilitam apontar quão significativo pode ser esse trabalho aparentemente banal, concordando com Burke, quando ele afirma:

\footnotetext{
Seja como for [...] um tema aparentemente tão frívolo e superficial quanto o do odor pode nos ajudar na tarefa de compreender as mentalidades e sensibilidades do passado.
}

(Burke, 2004, p. 2)

De fato, podemos também ir além do que Burke afirma ser a compreensão das mentalidades e sensibilidades do passado, pois, à medida que a rememoração acontece, o entrecruzamento de tempos e espaços se intensifica, não numa simples reconstrução do passado, mas numa elaboração do presente e do futuro a partir daquilo que é rememorado. As mentalidades e sensibilidades do passado estão guardadas nas memórias dos sujeitos estudantes da escola básica: crianças e jovens que experienciaram diferentes situações próprias e constitutivas do cotidiano escolar. Tantas cenas, tantos lugares - salas, pátios, corredores, quadras de esporte; tantos “outros" -, professores, colegas estudantes, inspetores de corredor... Todos esses são elementos e atores da cultura escolar que intensificam as relações desses sujeitos-professores-em-formação com a instituição e com as possibilidades do exercício profissional docente. Essas crianças e esses jovens do passado tornaram-se professores em formação inicial no presente e hoje passam pelos estágios em seus cursos de formação. As memórias acionadas pelos odores trazem, como já mencionamos, esses encontros com os sujeitos crianças-jovens-estudantes, agora em processo de constituição de sujeitos-docentes. 
Podemos lembrar de Josso que, ao assumir as histórias de vida como constitutivas da formação docente, afirma: "para que uma experiência seja considerada formadora, é necessário falarmos sob o ângulo da aprendizagem" (Josso, 2002). Isso implica dizer, como Souza, que:

A organização e construção da narrativa de si implicam colocar o sujeito em contato com suas experiências formadoras, as quais são perspectivadas a partir daquilo que cada um viveu/vive e das simbolizações e subjetivações construídas ao longo da vida. (Souza, 2004, p. 405)

A formação identitária docente - tema central das atuais pesquisas de nosso grupo - é permeada por essas aprendizagens e experiências formadoras que, como já afirmamos, pouco se relacionam com um currículo prescritivo, e muito se imbrica com aspectos estéticos dessa formação.

Ainda lembrando Josso, concordamos com Souza quando aponta:

Descortinar contextos, histórias e memórias através das narrativas implicadas dos sujeitos em formação, frente ao projeto de uma "abordagem experiencial” (Josso, 2002) de narrativas de histórias de vida, leva-me a caminhar no sentido de apreender marcas e implicações do itinerário escolar, da vivência escolar e suas relações com a(s) escola(s) e o papel exercidos por esses lugares/instituições na formação dos atores da pesquisa. (Souza, 2004, p. 414)

No caso desta pesquisa, o elemento inovador fica localizado na articulação entre a valorização de um caminho sensorial pouco usual (o olfato) e as memórias acionadas a partir dele, trazendo pistas de marcas importantes da constituição da identidade docente no contexto da formação inicial em atividades de estágio curricular. Em termos de conhecimentos produzidos, fica a assunção de que processos de formação docente podem ser currículos que propiciem encontros "consigo mesmo" que, oportunizados pela memória, não são exclusivamente do campo das racionalidades ou dos conhecimentos, mas sim potencializados pela sensibilidade e pela estética.

\section{Referências bibliográficas}

BENJAMIN, Walter. Obras escolhidas I- Magia e técnica, arte e política. Ensaios sobre literatura e história da cultura. 4. ed. São Paulo: Brasiliense, 1989.

BORGES, Cecília. Saberes docentes: diferentes tipologias e classificações de um campo de pesquisa. Educação \& Sociedade, Campinas, v. 22, n. 74, p. 59-76, 2001.

BURKE, Peter. Uma história cultural dos odores. Folha de S.Paulo, 15 fev. 2004. Caderno Mais. Disponível em: <www.http://www1.folha. uol.com.br/fsp/mais/fs1502200405.htm>. Acesso em: 10 abr. 2008. CERTEAU, Michel. A invenção do cotidiano: 1. Artes de fazer. 9. ed. Petrópolis: Vozes, 1994.

CORRADI, Dulcelena Peralis. Estágio supervisionado: cultura(s) e processos de identificação permeando um currículo de formação de professores de química. 102 f. Dissertação (Mestrado em Educação) - Faculdade de Educação, Universidade Estadual de Campinas, Campinas, 2005.

CUNHA, Renata C. O. B. Lembranças de escola na formação inicial de professores/as. In: PRADO, Guilherme do Val Toledo; CUNHA, Renata C. O. Barrichelo (Orgs.). Percursos de autoria: exercícios de pesquisa. Campinas: Alínea, 2007. p. 97-112.

FUJIKAWA, Mônica Matie. A escrita como pretexto de reflexão da prática pedagógica e como estratégia de intervenção na formação de professores. In: PRADO, Guilherme do Val Toledo; SOLIGO, Rosaura (Orgs.). Porque escrever é fazer história. São Paulo: Gráfica da FE, 2005. p. 229- 243.

GALZERANI, Maria Carolina Bovério. Percepções culturais do mundo da escola: em busca da rememoração. In: ENCONTRO NACIONAL DE PESQUISADORES DO ENSINO DE HISTÓRIA, 3., Campinas, 1999. Anais... Campinas: Gráfica da Faculdade de Educação da UNICAMP, 1999. p. 99-108.

Imagens entrecruzadas de infância e de produção de conhecimento histórico em Walter Benjamin. In:FARIA, Ana Lúcia Goulart et al. (Org.). Por uma cultura da infância: metodologias de pesquisa com crianças. Campinas: Autores Associados, 2002. p. 49-68.

GAUTHIER, C. et al. Por uma teoria da pedagogia. Pesquisas contemporâneas sobre o saber docente. Ijuí: UNIJUÍ, 1998.

GERALDI, Corinta Maria Grisólia et al. Cartografias do trabalho docente. Campinas: Mercado das Letras, 1998.

GOODSON, Ivor F. Dar voz ao professor: as histórias de vida dos professores e o seu desenvolvimento profissional. In: NÓVOA, António (Org.). Vidas de professores. Portugal: Porto, 1992. p. 63-78. 
Currículo, narrativa e o futuro social. Revista Brasileira de Educação, São Paulo, v. 12, n. 35, p. 241-252, 2007. JOSSO, Marie-Christine. Experiências de vida e formação. Lisboa: Educa, 2002.

LARROSA, Jorge. Notas sobre a experiência e o saber de experiência. Revista Brasileira de Educação, n. 19, p. 20-28, jan./abr. 2002.

LELIS, Isabel Alice. Do ensino de conteúdos ao saberes do professor: mudança de idioma pedagógico? Educação \& Sociedade, Campinas, v. 22, n. 74, p. 43-58, 2001.

LÜDKE, Menga. O professor, seu saber e sua pesquisa. Educação \& Sociedade, Campinas, v. 22, n. 74, p. 77-96, 2001.

NÓVOA, António. Os professores e as histórias da sua vida. In: (Org.). Vidas de professores. Portugal: Porto, 1992.

p. 11-30.

NUNES, Célia Maria Fernandes. Saberes docentes e formação de professores: um breve panorama da pesquisa brasileira. Educação \& Sociedade, Campinas, v. 22, n. 74, p. 27-42, 2001.

OLIVEIRA, Valeska Fortes de. A formação de professores revisita os repertórios guardados na memória. In: (Org.)

Imagens de professor - significações do trabalho docente. 2. ed. Ijuí: UNIJUÍ, 2004.

PÉREZ, Carmen Lúcia Vidal. O lugar da memória e a memória do lugar na formação de professores: a reinvenção da escola como uma comunidade investigativa. In: REUNIÃO ANUAL DA ANPEd, 26. 2003, Caxambu. Anais... Caxambu: ANPEd, 2003. 1 CD-ROM.

ROSA, Maria Inês Petrucci. Investigação e ensino: articulações e possibilidades na formação de professores de ciências. Ijuí: Ed. UNIJUÍ, 2004.

; TOSTA, Andréa H. O lugar da química na escola movimentos constitutivos da disciplina no cotidiano escolar. Revista Ciência e Educação, Bauru, v. 11, n. 2, p. 253-262, 2005.

ROSA, Maria Inês Petrucci; CORRADI, Dulcelena. Peralis. Cultura(s) e processos de identificação em currículo de formação docente: uma experiência no estágio da licenciatura. Revista Horizontes, Bragança Paulista, v. 25, n. 1, p. 66-79, 2007.

SOUZA, Elizeu Clementino. O conhecimento de si, as narrativas de formação e o estágio: reflexões teórico-metodológicas sobre uma abordagem experiencial de formação inicial de professores. In: ABRAHÃO, Maria Helena Menna Barreto(Org.). A aventura (auto)biográfica: teoria e empiria. Porto Alegre: EdiPUCRS, 2004. p. 387-418.

TARDIF, Maurice. Saberes docentes e formação docente. Petrópolis: Vozes, 2002.

VEIGA-NETO, Alfredo. Olhares. In: COSTA, Marisa Vorraber

(Org.). Caminhos investigativos: novos olhares na pesquisa em educação. Rio de Janeiro: DP\&A, 2002.
MARIA INÊS PETRUCCI ROSA, doutora em educação pela Universidade Estadual de Campinas (UNICAMP), é professora do Departamento de Ensino e Práticas Culturais da Faculdade de Educação da mesma universidade e membro do Grupo de Estudos e Pesquisas em Educação Continuada (GEPEC). Publicações recentes: "Experiências interdisciplinares e formação de professore(a) s de disciplinas escolares - imagens de um currículo - diáspora" (Pro-Posições, v. 18, n. 2, p. 10-25, 2007); Investigação e ensino: articulações e possibilidades na formação de professores de ciências (Ijuí: Ed. UNIJUÍ, 2004); “Cotidiano da escola: as lentes do cinema propiciando outros olhares e outras histórias" (In: CAMARGO, Ana Maria Faccioli; MARIGUELA, Márcio (Orgs.). Cotidiano escolar: emergência e invenção. Piracicaba: Jacintha, 2007. p. 4152). Pesquisa em andamento: "Formação docente em disciplinas escolares: políticas e identidades no contexto da cultura escolar". E-mail: inesrosa@unicamp.br

TACITA ANSANELLO RAMOS, mestre em educação pela Universidade Estadual de Campinas (UNICAMP), é professora de física da rede pública de ensino do estado de São Paulo e membro do Grupo de Estudos e Pesquisas em Educação Continuada (GEPEC). Publicações recentes: em co-autoria com PAVAN, Adriana C.; PARMA, Marivaldo; CORRADI, Dulcelena Peralis; SILVA, Mirian P.; OLIVEIRA, Ana Carolina G.; BONAMIGO, Celisa C.; CARRERI, Andréa V.; ROSA, Maria Inês Petrucci, "Narrar currículos: inventando tessituras metodológicas" (In: AMORIM, Antonio Carlos Rodrigues de (Org.). Passagens entre moderno para o pós-moderno: ênfases e aspectos metodológicos das pesquisas sobre currículo. Campinas: Faculdade de Educação da UNICAMP, GT Currículo da ANPEd, v. 1, 2007, p. 29-35); "Cultura material escolar: o lugar da química e as reformas curriculares pós anos 90 " (In: ENCONTRO PAULISTA DE PESQUISA EM ENSINO DE QUÍMICA, 4., São Paulo, 2007. Anais... São Paulo: A formação do pesquisador, 2007); em co-autoria com ROSA, Maria Inês Petrucci, "A disciplina escolar química e seu lugar no cotidiano da escola - ampliando o debate" (In: ENCONTRO NACIONAL DE ENSINO DE QUÍMICA, 13., 2006, Campinas. Anais... Campinas: s.ed., 2006). Pesquisa em andamento: "Cultura(s) escolar(es): o lugar da química e os consumos de propostas curriculares para o ensino médio".E-mail: tacita_ramos@yahoo.com.br

Recebido em janeiro de 2008 Aprovado em julho de 2008 
implementado en Brasil por Getúlio

Vargas. La sustentación teórica del estudio se encuentra en el campo de la etnomatemática - constituido mediante los entrecruzamientos de las teorías post estructuralistas, en especial el pensamiento de Michel Foucault, y de las ideas formuladas por Ludwig Wittgenstein en su obra Investigações filosóficas. El material de investigación examinado en el artículo consiste en narraciones producidas por siete colonos que estudiaron en aquella escuela en el período enfocado y en un texto elaborado por uno de los participantes de la pesquisa. El ejercicio analítico realizado, mostró que: la matemática escolar practicada en aquella institución fue siendo constituida como un conjunto de juegos de lenguaje marcados por la escritura y por el formalismo; las matemáticas generadas en las actividades cotidianas de los participantes del estudio, pueden ser significadas como ajustando juegos de lenguaje regidos por otra gramática, que utilizaba reglas como la oral, la desorganización, la estimativa y arredondando las cifras, constituyendo criterios de racionalidad diferentes de aquellos presentes en los juegos que engendraban la matemática local.

Palabras clave: matemática escolar; etnomatemática; teorías post estructuralistas

Maria Inês Petrucci Rosa e Tacita Ansanello Ramos

\section{Memórias e odores: experiências curriculares na formação docente Este artigo trata de memórias escolares de estudantes de licenciatura com- partilhadas na experiência do estágio,}

tendo como princípio de formação uma aproximação mais significativa com os fazeres do cotidiano escolar. Metodologicamente, a investigação questiona a clássica abordagem de produção de conhecimentos a partir do olhar, trazendo como elemento inovador a articulação entre a valorização de um caminho sensorial pouco usual - o olfato - e as memórias acionadas a partir dele. $\mathrm{Na}$ intenção de exercitar a possibilidade da escrita de histórias narrativas a partir de odores, foram propostas aos alunos as seguintes questões: que odores são sentidos no ambiente da escola onde se realiza seu estágio? Que memórias são acionadas a partir desses odores? Defendemos a idéia de que a formação docente passa também pelas memórias, muitas vezes inusitadas, pelas experiências comunicáveis e pelas sensibilidades dos professores em formação. Palavras-chave: formação docente; estágio supervisionado; memórias; narrativas; odores

\section{Memories and smells: curricular} experiences in teacher training This article deals with the shared school memories of undergraduate students during placement experience, promoting a more meaningful approximation with the daily life of the school as a principle of teacher training. Methodologically the investigation questions the conventional approach to the production of knowledge based on looking, and introduces as the innovative element the link between the promotion of that unusual sensory path - the smell and the memories triggered by it. The following questions were put to the students with the intention of exercising the possibility of writing stories based on these smells: what smells were perceived in the school environment where you did your placement? What memories were triggered by these odours? We defend the idea that teacher training is also transmitted by the often unusual memories, communicated by the experiences and the sensibilities of the teachers in training.

Key words: teacher training; supervised placement; memories; narratives; smells

Memorias y olores: experiencias curriculares en la formación docente

Este artículo trata de memorias escolares de estudiantes de licenciatura compartidas en la experiencia de la práctica, teniendo como principio de formación una aproximación más significativa con los hechos del cotidiano escolar. Metodológicamente, la investigación cuestiona la clásica abordaje de producción de conocimientos a partir de la mirada, trayendo como elemento innovador la articulación entre la valorización de un camino sensorial poco común - el olfato - y las memorias accionadas a partir de él. Con la intención de ejercitar la posibilidad de escribir historias narrativas a partir de olores, fueron propuestas a los alumnos las siguientes cuestiones: ¿qué olores son sentidos en el ambiente de la escuela donde se realiza su práctica? ¿Qué memorias son accionadas a partir de esos olores? Defendemos la idea de que la formación docente pasa también por las memorias, muchas veces inusitadas, por las experiencias comunicables y por las sensibilidades de los profesores en formación.

Palabras clave: formación docente; práctica supervisionada; memorias narrativas; olores 